\title{
Characterization and Identification of the Major Flavonoids in Phyllostachys edulis Leaf Extract by UPLC-QTOF-MS/MS
}

\author{
S.-Y. Shao, Y. Ting, J. Wang, J. Sun and X.-F. Guo* \\ International Centre for Bamboo and Rattan, National Forestry and Grassland Administration, Beijing, China
}

Received: 05 Aug 2019; accepted: 18 Oct 2019

\begin{abstract}
Phyllostachys edulis (PES), the most important bamboo species in China, is widely distributed in East Asia. Flavonoids, which are important bioactive natural compounds, often have similar structures, making their structural elucidation difficult. The aim of this study was to represent valuable, reliable mass spectral data for the identification of flavonoids in plant leaves. Ultra-performance liquid chromatography-quadrupole time-of-flight mass spectrometry (UPLC-Q-TOF-MS/MS) method was established for characterization and identification of the major flavonoids in PES leaf extract. A total of 13 flavonoids were simultaneously characterized, and their proposed characteristic product ions and fragmentation pathways were investigated. Thirteen compounds were separated on an Agilent Zorbax RRHD SB-C18 column $(150 \mathrm{~mm} \times 2.1 \mathrm{~mm}, 1.8 \mu \mathrm{m})$. On the basis of comparing with the 4 reference standards and the literature data, the other 9 flavonoids were identified by tandem mass spectrometry (MS/MS). Eight compounds (compounds 1, 4, 5, 8, 9, 10,11, and 12) were found in PES leaves for the first time. An efficient UPLCQTOF-MS/MS method was successfully applied for the structural identification of flavonoids in PES leaves. These results have practical applications for the rapid identification and structural characterization of these compounds in crude bioactive extracts or mixtures.
\end{abstract}

Keywords: UPLC-QTOF-MS/MS, flavonoids, fragmentation pathway, Phyllostachys edulis (PES)

\section{Introduction}

Phyllostachys edulis (PES) is widely distributed in East Asia and is the most important bamboo species in China [1]. In addition, the bamboo leaf is easily accessible and inexpensive. To date, bamboo leaf extract has been reported to exhibit antioxidant, antibacterial, antitumor, anti-inflammatory, antimicrobial, and antiulcerogenic activities [2-6]. Phytochemical research on PES leaves has revealed the functions of 4 flavonoids and their working mechanisms [7]. Flavonoids are thought to be biologically active natural products present in a variety of fruits, vegetables, grains, and other dietary supplements [8-10]; flavonoids have attracted substantial attention because of their antioxidant abilities, chemopreventive properties, and radical scavenging activities, as well as cardiovascular protective, anti-inflammatory, and antiviral effects [11-17]. There is a growing interest in the analysis and identification of the flavonoid constituents of medicinal plants to identify the structure-activity relationship of flavonoids, as a small difference in the structure of a flavonoid can cause significant changes in its biological activities [18-20].

According to the differences in the aglycone, sugar group, glycosidic bond, and glycosylation positions, flavone glycosides are classified as different structural types flavone glycosides, and the type is correlated with the biological activities; therefore, it is important to use a rapid method to determine the true molecular structure of such compounds. Mass spectrometry (MS) has been widely used for the structural determination of flavonoids [21, 22]. Liquid chromatography combined with tandem mass spectrometry (LC-MS) has been shown to be a valuable technique with high sensitivity and

* Author for correspondence: gxf71622@icbr.ac.cn. high resolution; recently, it has been widely applied to the structural characterization and isomeric differentiation of flavonoids using both positive and negative ion modes [23-26]. The application of mass spectrometry in the structural analysis of flavonoids has been reviewed in detail [27-29]. With the development of LC-MS, a useful approach, ultra-performance liquid chromatography coupled with quadrupole time-of-flight mass spectrometry (UPLC-QTOF-MS/MS), has become a very powerful tool for analyzing and identifying chemical compounds in complex samples due to its high resolution and high sensitivity $[30,31]$.

In this paper, an efficient UPLC-QTOF-MS/MS method was established for the rapid chemical profiling in leaves. A total of 13 flavonoids were simultaneously characterized, and their proposed characteristic product ions and fragmentation pathways were investigated. The results provided valuable mass spectral data and reliable information for the identification of flavone $C$-glycosides, flavone $O$-glycosides, flavone di-C, $O$-glycosides, and flavone $C$-diglycosides present in herbs or foods.

\section{Experimental}

2.1. Plant Material. Bamboo (Phyllostachys edulis) leaves were collected from Nanchang, Jiangxi Province, China. The fresh leaves were dried in the shade and then powdered and deposited. A voucher specimen was deposited in the State Forestry Administration Key Open Laboratory, International Centre for Bamboo and Rattan (ICBR), Beijing, China.

2.2. Chemicals and Solvents. All reagents were purchased from Beijing Chemical Works (Beijing, China), unless otherwise specified. Methanol (HPLC grade) and acetonitrile (HPLC grade) were purchased from Merck (Darmstadt, Germany). Formic acid (mass spectrometry grade) was

This is an open-access article distributed under the terms of the Creative Commons Attribution-NonCommercial 4.0 International License (https://creativecommons.org/licenses/by-nc/4.0/), which permits unrestricted use, distribution, and reproduction in any medium for non-commercial purposes, provided the original author and source are credited, a link to the CC License is provided, and changes - if any - are indicated. 
obtained from Sigma (St, Louis, MO). The water used in the experiments was purified using a Milli-Q system (Millipore, Inc. Milford, MA). Four reference standards, namely, orientin (luteolin-8-C-glucoside) (2), isoorientin (luteolin-6- $C$ glucoside) (3), vitexin (apigenin-8- $C$-glucoside) (6), and isovitexin (apigenin-6- $C$-glucoside) (7), were isolated in our laboratory.

2.3. Extraction, Isolation, and Sample Preparation. The shade-dried leaves of PES $(5 \mathrm{~kg})$ were extracted three times with $95 \%$ ethanol by cold percolation. The removal of the solvent by evaporation can give a residue $(308 \mathrm{~g})$. The residue was suspended in $\mathrm{H}_{2} \mathrm{O}$ and partitioned by petroleum ether. The water solution was concentrated and subjected to a macroporous absorption resin (Diaion HP-20, Mitsubishi Chemical Corp., Tokyo, Japan) with an isocratic elution of $40 \%$ ethanol. Then, the $40 \%$ ethanol fraction was applied to a preparative HPLC using a Shimadzu LC-6 AD instrument with an SPD-20A detector (Shimadzu, Kyoto, Japan) and a YMC-Pack ODS-A column $(250 \times 20 \mathrm{~mm}, 5 \mu \mathrm{m}$, YMC, Kyoto, Japan) and eluted with acetonitrile-water $(14: 86, v / v)$ to yield compounds 2, 3, 6, and 7. The structures of compounds 2, 3, 6, and 7 were determined by detailed spectroscopic analysis (NMR and HRESIMS). The purities of these compounds were determined to be higher than $95 \%$ by a Waters 2695 system and a PDA detector 2996 (Waters, Milford, MA, USA) with a YMC-Pack ODS-AQ C18 column $(250 \times 4.6 \mathrm{~mm}, 5 \mu \mathrm{m}, \mathrm{YMC})$. All the reference standards were dissolved in methanol to prepare solutions with final concentrations of $0.02 \mathrm{mg} / \mathrm{mL}$ for UPLC-QTOF-MS/MS analysis. The $40 \%$ ethanol fraction was dissolved in methanol-water $(1: 1, v / v)$, then a $5 \mathrm{mg} / \mathrm{mL}$ stock solution was filtered through a $0.2-\mu \mathrm{m}$ polytetrafluoroethylene (PTFE) syringe filter, and the filtrate was subjected to UPLC-QTOFMS/MS analysis.

2.4. NMR Analysis. The nuclear magnetic resonance (NMR) spectra were run with a Bruker AV300NMR spectrometer at $300 \mathrm{MHz}$ (Bruker, Zurich, Switzerland) using DMSO- $d_{6}$ as the solvent and tetramethylsilane (TMS) as an internal standard. Chemical shifts are expressed in $\delta(\mathrm{ppm})$, and coupling constants are reported in hertz. The NMR spectra of 4 reference standards are included in the supporting information.

2.5. UPLC-QTOF-MS/MS Analysis. Experiments were performed with an Agilent UPLC 1290 system (Agilent Technologies, Santa, Clara, CA, USA) coupled with a highresolution quadrupole time-of-flight MS/MS 6540 system (Agilent Technologies, Santa, Clara, CA, USA) equipped with a JetStream technology ESI ion source that was operated in the negative ionization mode. For chromatographic analysis, an Agilent Zorbax RRHD SB-C18 column (150 mm $\times 2.1 \mathrm{~mm}, 1.8 \mu \mathrm{m}$, Agilent Technologies, USA) was used. For analyses conducted in the negative ion mode, mobile phase A consisted of $0.1 \%(v / v)$ formic acid in ultrapure water, and mobile phase B consisted of $0.1 \%(v / v)$ formic acid in methanol. The linear gradient elution program was optimized as follows: $75 \%$ mobile phase A (0-60 min), 75$70 \%$ mobile phase A (60-100 $\mathrm{min})$, and $70-60 \%$ mobile phase A (100-120 min). The flow rate was $140 \mu \mathrm{L} / \mathrm{min}$. The column temperature was maintained at $30{ }^{\circ} \mathrm{C}$. The injection volume was $10 \mu \mathrm{L}$. The recorded UV spectra were between 190 and $400 \mathrm{~nm}$. The mass spectrometer was equipped with a JetStream technology ESI source. The source parameters were in negative ionization mode as follows: gas temperature: $350{ }^{\circ} \mathrm{C}$, drying gas flow rate: $8 \mathrm{~L} / \mathrm{min}$, nebulizer pressure: 35 psig, sheath gas temperature: $350{ }^{\circ} \mathrm{C}$, sheath gas flow rate: $11 \mathrm{~L} / \mathrm{min}$, VCap: $3500 \mathrm{~V}$, nozzle voltage (Expt): $1000 \mathrm{~V}$, fragmentor voltage: $200 \mathrm{~V}$, skimmer voltage: $65 \mathrm{~V}$, OCT $1 \mathrm{RF}$
Vpp: $750 \mathrm{~V}$, collision energy: 10-30 eV (in step of $5 \mathrm{eV}$ ), collision gas: $\mathrm{N}_{2}$, and collision cell: hexapole. The scan range was $m / z \quad 50-1000$ for the MS scan and $m / z 50-800$ for the MS/MS scan.

\section{Results and Discussion}

3.1. UPLC-QTOF-MS/MS Analysis Phyllostachys edulis Leaves Flavonoids. UPLC-UV chromatograms collected at $350 \mathrm{~nm}$ and UPLC-QTOF-MS extracted ion chromatograms (EIC) of the major flavonoids in the PES leaves are shown in Figure 1. The major flavonoids characterized in the PES leaves by UPLC-QTOF-MS/MS are shown in Table 1, and Table 1 summarizes the theoretical and experimental masses, retention times, formulas, and fragment ions of the deprotonated ions of these major flavonoids. All the compounds were identified by an interpretation of their retention times, MS and MS/MS spectra, and a comparison with the data provided in the literature, in which it was important to analyze the relative abundances of the fragments, in addition to observing mass loss during the fragmentation events. Flavones represented the main subclass of flavonoids observed in the PES leaves, and the main flavones identified are luteolin and apigenin, formed by monoglycosides and diglycosides from different sugar units (hexoses, pentoses, and rhamnose). The nomenclature of product ions created after cleavage of the glycosidic bonds follows that proposed by Domon and Costello [32] and by $\mathrm{Ma}$ and others [33] (Scheme 1).

3.2. QTOF-MS/MS Analysis of Pure Standards. For the structural identification and the mass spectrometry fragmentation pathways of flavonoids and their glycosides in PES leaves, known compounds are analyzed by quadrupole time-of-flight tandem mass spectrometry (QTOF-MS/MS) to determine the specificity of the MS/MS spectral pattern of each structure. Product ion spectra of deprotonated ion [M $\mathrm{H}]^{-}$of compounds 2, 3, 6, and 7 (orientin, isoorientin, vitexin, and isovitexin, respectively) in the negative ion mode are shown in Figure 2.

First, orientin $(\mathrm{RT}=31.81 \mathrm{~min})$ and isoorientin $(\mathrm{RT}=38.86$ min) yielded a deprotonated ion $[\mathrm{M}-\mathrm{H}]^{-}$at $\mathrm{m} / \mathrm{z} 447.0951$ and $\mathrm{m} / \mathrm{z}$ 447.0965. The tandem mass spectrum of orientin showed a fragment ion at $m / z 429.0958\left(\left[\mathrm{M}-\mathrm{H}-\mathrm{H}_{2} \mathrm{O}\right]^{-}\right)$, which corresponded to the losses of a molecule $\mathrm{H}_{2} \mathrm{O}$ (18 Da) between the 2"-hydroxyl group of the sugar and the 5 or 7-hydroxyl group of the aglycone. The fragment ions at $\mathrm{m} / \mathrm{z}$ $357.0694\left({ }^{0,3} \mathrm{X}_{0}^{-}\right), \mathrm{m} / \mathrm{z} 327.0585\left({ }^{0,2} \mathrm{X}_{0}^{-}\right)$, and $\mathrm{m} / \mathrm{z} 297.0468$ $\left({ }^{0,1} \mathrm{X}_{0}^{-}\right)$indicate the losses of $\mathrm{C}_{3} \mathrm{H}_{6} \mathrm{O}_{3}\left(\begin{array}{ll}90 & \mathrm{Da}\end{array}\right), \mathrm{C}_{4} \mathrm{H}_{8} \mathrm{O}_{4}$ $(120 \mathrm{Da})$, and $\mathrm{C}_{5} \mathrm{H}_{10} \mathrm{H}_{5}(150 \mathrm{Da})$ from the $[\mathrm{M}-\mathrm{H}]^{-}$, respectively, which are characteristic of the cross-ring cleavage of the glucose part of the flavonoid glycosyl moiety. The characteristic product ion at $m / z 339.0590\left(\left[{ }^{0,3} \mathrm{X}_{0}-\mathrm{H}_{2} \mathrm{O}\right]^{-}\right)$was generated by the loss of $\mathrm{H}_{2} \mathrm{O}$ from ${ }^{0,3} \mathrm{X}_{0}^{-}$. The relative abundances of these two ions $\left({ }^{0,3} \mathrm{X}_{0}^{-},\left[{ }^{0,3} \mathrm{X}_{0}-\mathrm{H}_{2} \mathrm{O}\right]^{-}\right)$in compound 3 were much higher than those in compound 2.

Vitexin $(\mathrm{RT}=45.89 \mathrm{~min})$ and isovitexin $(65.76 \mathrm{~min})$ gave a deprotonated ion $[\mathrm{M}-\mathrm{H}]^{-}$at $\mathrm{m} / \mathrm{z} 431.0994$ and $\mathrm{m} / \mathrm{z}$ 431.0977. In the tandem mass spectrum of vitexin, the fragmentation ions at $\mathrm{m} / \mathrm{z} 341.0710\left({ }^{0,3} \mathrm{X}_{0}^{-}\right)$and $\mathrm{m} / \mathrm{z} 311.0633$ $\left({ }^{0,2} \mathrm{X}_{0}^{-}\right)$were due to the losses of $\mathrm{C}_{3} \mathrm{H}_{6} \mathrm{O}_{3}(90 \mathrm{Da})$ and $\mathrm{C}_{4} \mathrm{H}_{8} \mathrm{O}_{4}$ $(120 \mathrm{Da})$ from the $[\mathrm{M}-\mathrm{H}]^{-}$ion, respectively, from the crossring cleavages of the hexose unit. The product ions at $\mathrm{m} / \mathrm{z}$ $283.0687\left(\left[{ }^{0,2} \mathrm{X}_{0}-\mathrm{CO}\right]^{-}\right)$were produced by the loss of $\mathrm{CO}$ $(28 \mathrm{Da})$ from the $m / z 311.0633\left({ }^{0,2} \mathrm{X}_{0}^{-}\right)$ion. The loss of $\mathrm{H}_{2} \mathrm{O}$ (18 Da) from $\mathrm{m} / \mathrm{z} 341.0710\left({ }^{0,3} \mathrm{X}_{0}^{-}\right)$led to the formation of $\mathrm{m} / \mathrm{z}$ $323.0557\left(\left[{ }^{0,3} \mathrm{X}_{0}-\mathrm{H}_{2} \mathrm{O}\right]^{-}\right)$. Differentiation between vitexin and isovitexin was achieved by observing the fragment 


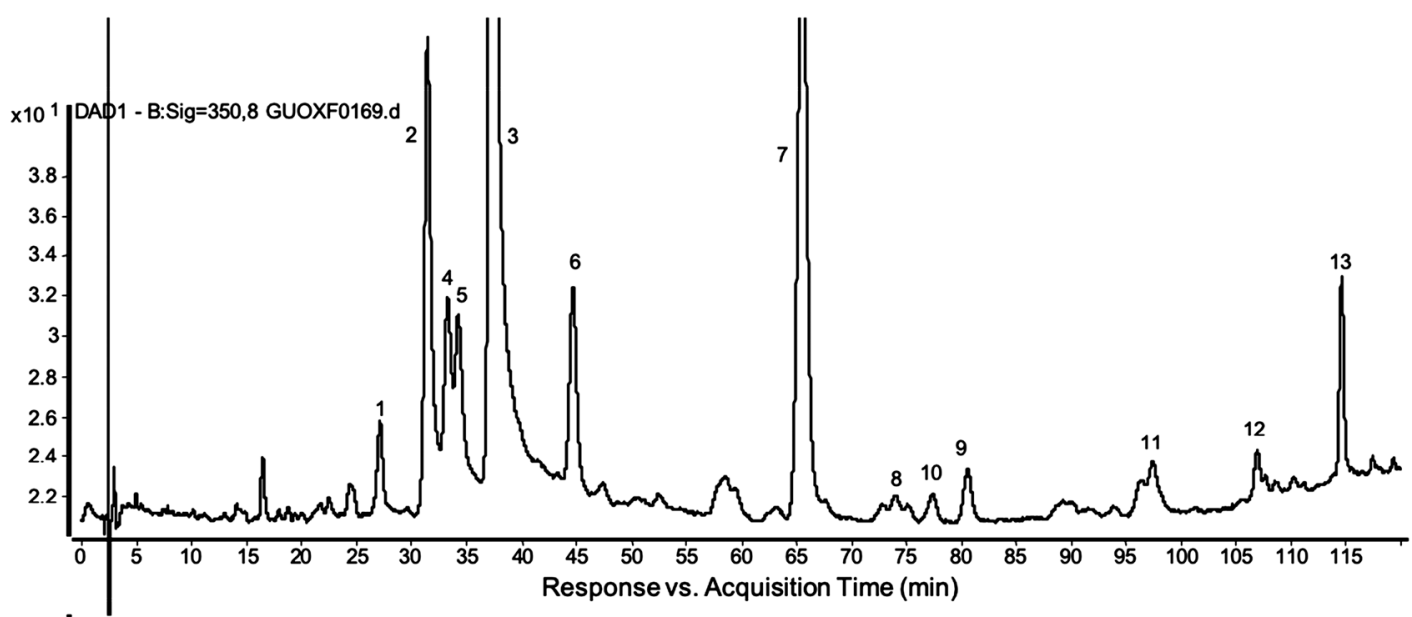

x10 2 -ESI EIC(593.1458) Full scan Frag=200.0V GUOXF0169.d

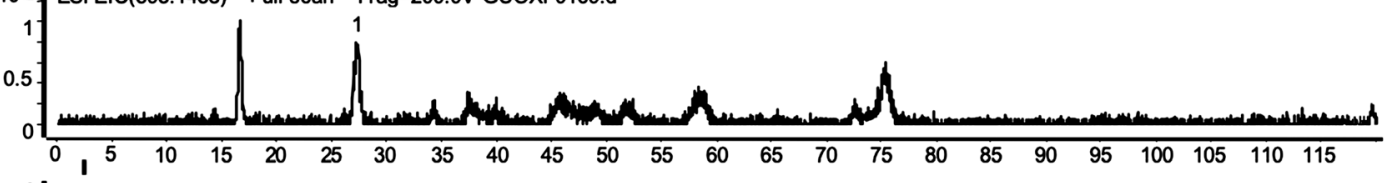
x10 2 -ESI EIC(447.0988) Full scan Frag=200.0V GUOXF0169.d

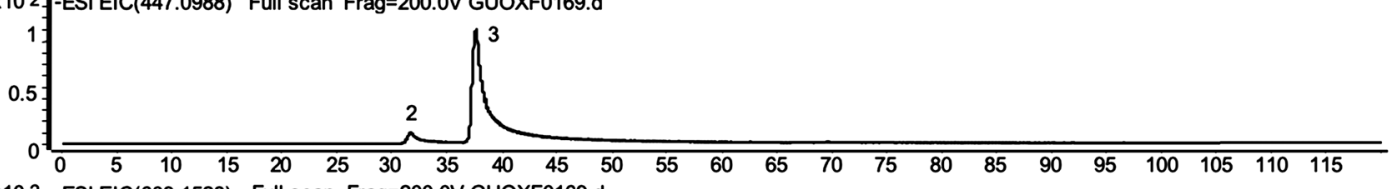

$\times 10^{2}$-ESI EIC(609.1528) Full scan Frag=200.0V GUOXF0169.d

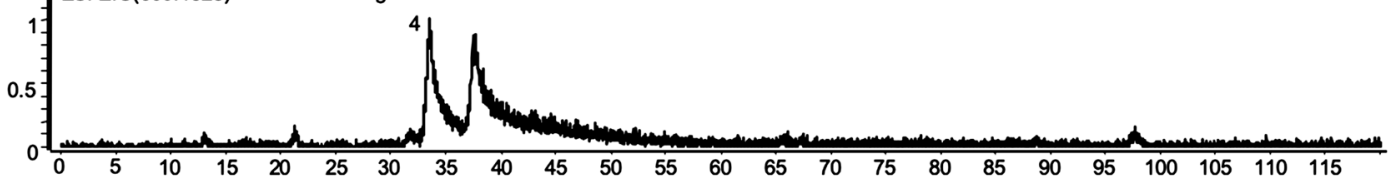
$\times 10^{2}$-ESI EIC(579.1350) Full scan Frag=200.0V GUOXF0169.d

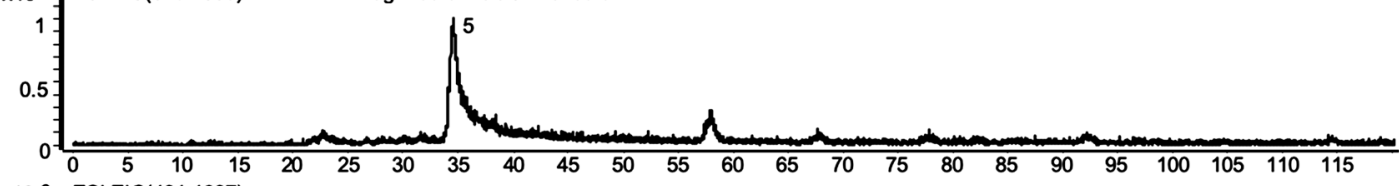
x10 2 TESI EIC(431.1037) Full scan Frag=200.0V GUOXF0169d

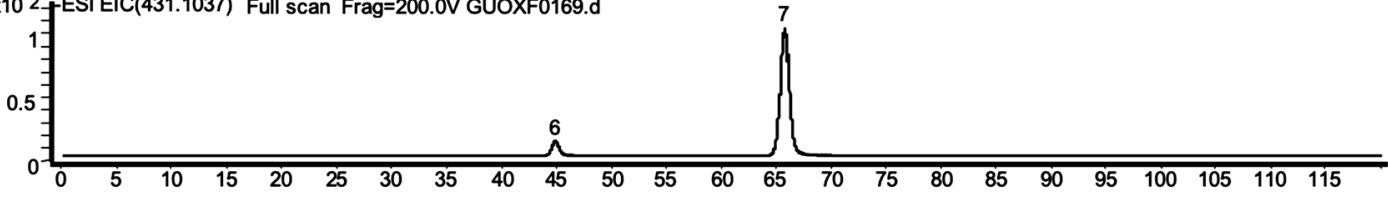
$x 102$-ESI EIC(461.1058) Full scan Frag=200.0V GUOXF0169.d

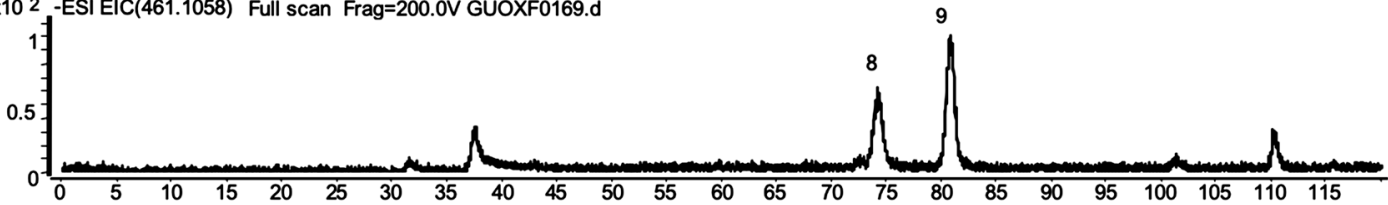

Fill

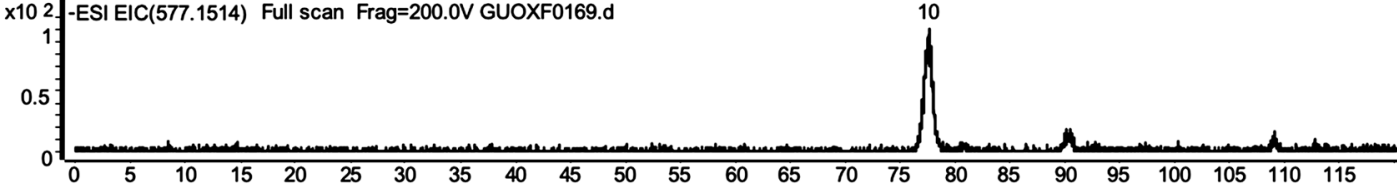
$\times 102$-ESI EIC(417.0790) Full scan Frag=200.0V GUOXF0169.d
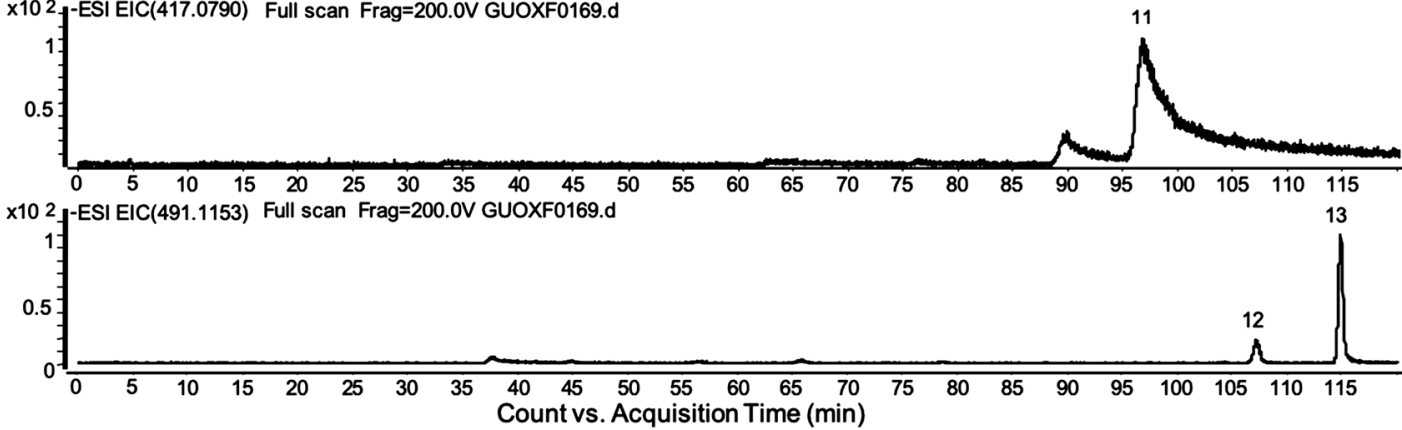

Figure 1. UPLC-UV chromatograms acquired at $350 \mathrm{~nm}$ and UPLC-Q-TOF-MS extracted ion chromatograms (EIC) of the major flavonoids in the PES leaves 
Table 1. The major flavonoids characterized in the PES leaves by UPLC-QTOF-MS/MS

\begin{tabular}{|c|c|c|c|c|c|c|c|}
\hline$\overline{\text { No. }}$ & $\begin{array}{l}\text { Retention } \\
\text { time (min) }\end{array}$ & Formula & $\begin{array}{c}\text { Theoretical } \\
{[\mathrm{M}-\mathrm{H}]^{-1}(\mathrm{~m} / \mathrm{z})}\end{array}$ & $\begin{array}{c}\text { Experimental } \\
{[\mathrm{M}-\mathrm{H}]^{-}(\mathrm{m} / \mathrm{z})}\end{array}$ & $\begin{array}{l}\text { Error } \\
(\mathrm{ppm})\end{array}$ & Fragment ions & Tentative identification \\
\hline 1 & 27.43 & $\mathrm{C}_{27} \mathrm{H}_{30} \mathrm{O}_{15}$ & 593.1512 & 593.1518 & -1.0 & $\begin{array}{l}\text { 473.1126, 431.1056, 341.0607, } \\
323.0576,311.0614,297.0482\end{array}$ & Isovitexin-4'-O-glucoside \\
\hline 2 & 31.81 & $\mathrm{C}_{21} \mathrm{H}_{20} \mathrm{O}_{11}$ & 447.0933 & 447.0951 & -4.1 & $\begin{array}{l}429.0958,357.0694,339.0590 \\
327.0585,297.0457,285.0472\end{array}$ & $\begin{array}{l}\text { Luteolin-8-C-glucoside } \\
\text { (orientin) }\end{array}$ \\
\hline 3 & 38.86 & $\mathrm{C}_{21} \mathrm{H}_{20} \mathrm{O}_{11}$ & 447.0933 & 447.0965 & -7.2 & $\begin{array}{l}429.0915,357.0692,339.0588, \\
327.0583,297.0471,285.0469\end{array}$ & $\begin{array}{l}\text { Luteolin-6-C-glucoside } \\
\text { (isoorientin) }\end{array}$ \\
\hline 4 & 33.71 & $\mathrm{C}_{27} \mathrm{H}_{30} \mathrm{O}_{16}$ & 609.1461 & 609.1502 & -6.7 & $\begin{array}{c}489.1123,447.0990,429.0924 \\
357.0652,339.0669,327.0580 \\
309.0453,285.0442\end{array}$ & Isoorientin-2"-O-glucoside \\
\hline 5 & 34.97 & $\mathrm{C}_{26} \mathrm{H}_{28} \mathrm{O}_{15}$ & 579.1355 & 579.1318 & 6.5 & $\begin{array}{c}459.1029,429.0925,447.1043 \\
357.0701,339.0577,327.0588, \\
309.0485,285.0471\end{array}$ & Isoorientin-2"-O-arabinoside \\
\hline 6 & 45.89 & $\mathrm{C}_{21} \mathrm{H}_{20} \mathrm{O}_{10}$ & 431.0984 & 431.0994 & -2.4 & $\begin{array}{c}341.0710,323.0557,311.0633 \\
283.0687,268.0390\end{array}$ & $\begin{array}{l}\text { Apigenin-8-C-glucoside } \\
\text { (vitexin) }\end{array}$ \\
\hline 7 & 65.76 & $\mathrm{C}_{21} \mathrm{H}_{20} \mathrm{O}_{10}$ & 431.0984 & 431.0977 & 1.6 & $\begin{array}{c}341.0742,323.0631,311.0626 \\
283.0674,269.0517\end{array}$ & $\begin{array}{l}\text { Apigenin-6- } C \text {-glucoside } \\
\text { (isovitexin) }\end{array}$ \\
\hline 8 & 74.37 & $\mathrm{C}_{22} \mathrm{H}_{22} \mathrm{O}_{11}$ & 461.1089 & 461.1093 & -0.8 & $\begin{array}{c}371.0827,341.0784,326.0458 \\
313.0748,298.0526\end{array}$ & $\begin{array}{l}\text { Luteolin-3'-methoxy-8- } \\
\text { C-glucoside }\end{array}$ \\
\hline 9 & 81.21 & $\mathrm{C}_{22} \mathrm{H}_{22} \mathrm{O}_{11}$ & 461.1089 & 461.1068 & 4.6 & $\begin{array}{c}371.0773,341.0619,326.0426 \\
313.0710,298.0507\end{array}$ & $\begin{array}{l}\text { Luteolin-3'-methoxy-6- } \\
\text { C-glucoside }\end{array}$ \\
\hline 10 & 76.91 & $\mathrm{C}_{27} \mathrm{H}_{30} \mathrm{O}_{14}$ & 577.1563 & 577.1552 & 1.9 & $\begin{array}{l}457.1158,431.0808,413.0879, \\
353.0675,341.0663,323.0548, \\
311.0562,293.0472,269.0407\end{array}$ & Isovitexin-2"-O-rhamnoside \\
\hline 11 & 98.07 & $\mathrm{C}_{20} \mathrm{H}_{18} \mathrm{O}_{10}$ & 417.0827 & 417.0799 & 6.7 & $\begin{array}{l}399.0666,357.0608,339.0503, \\
327.0503,297.0472,285.0415\end{array}$ & Luteolin-6-C-arabinoside \\
\hline 12 & 107.28 & $\mathrm{C}_{23} \mathrm{H}_{24} \mathrm{O}_{12}$ & 491.1195 & 491.1233 & -7.7 & $\begin{array}{c}476.0862,461.0649,329.0679 \\
314.0425,299.0204\end{array}$ & Tricin-4'-O-glucoside \\
\hline 13 & 115.05 & $\mathrm{C}_{23} \mathrm{H}_{24} \mathrm{O}_{12}$ & 491.1195 & 491.1192 & 0.6 & $\begin{array}{l}476.0946,461.0714,328.0593 \\
313.0355,299.0204,285.0419\end{array}$ & Tricin-7-O-glucoside \\
\hline
\end{tabular}
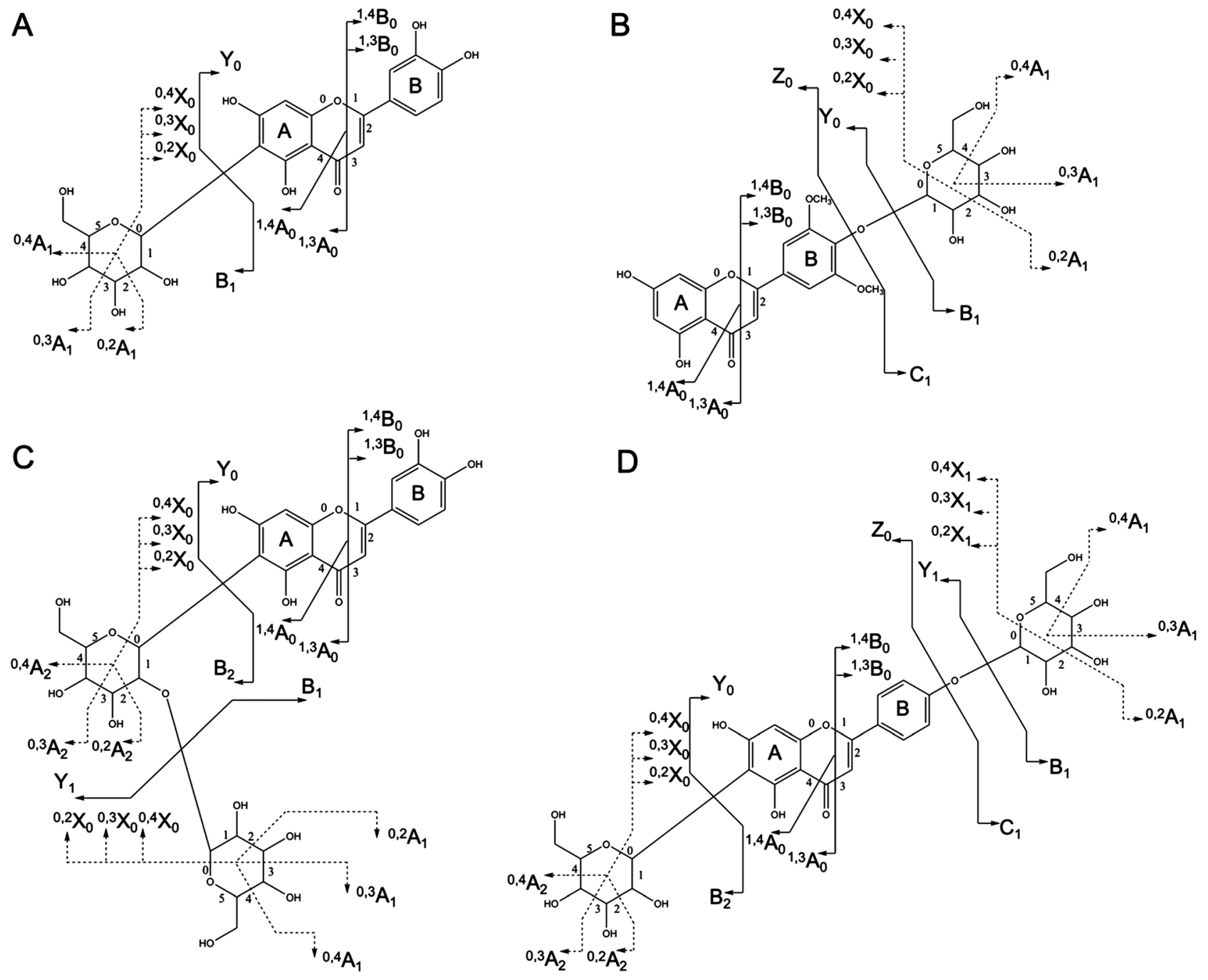

Scheme 1. Fragmentation nomenclature commonly used for flavonoids (A luteolin-8-C-glucoside; B tricin-4'-O-glucoside; C isoorientin-2"-O-glucoside; D isovitexin-4'-O-glucoside), according to Domon and Costello [32] and by Ma and others [33]. 
$\%$

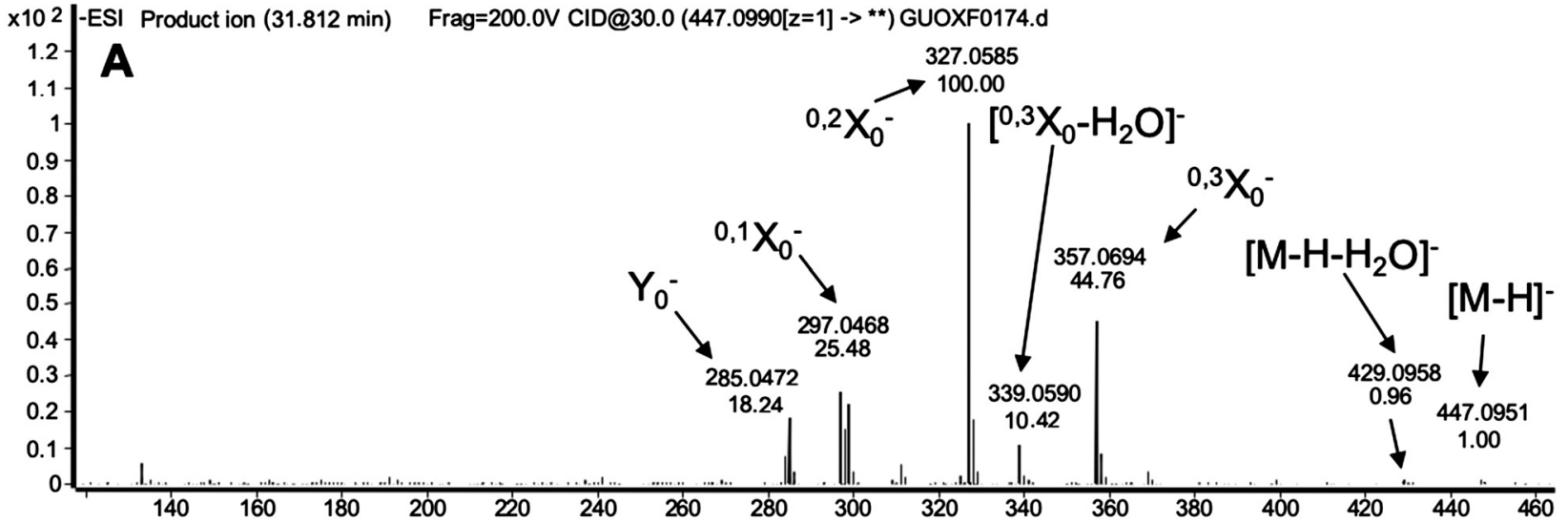

x10 2 -ESI Product ion (38.863 min) Frag=200.0V CID@30.0 (447.0990[z=1] $\rightarrow$ **) GUOXF0174.d

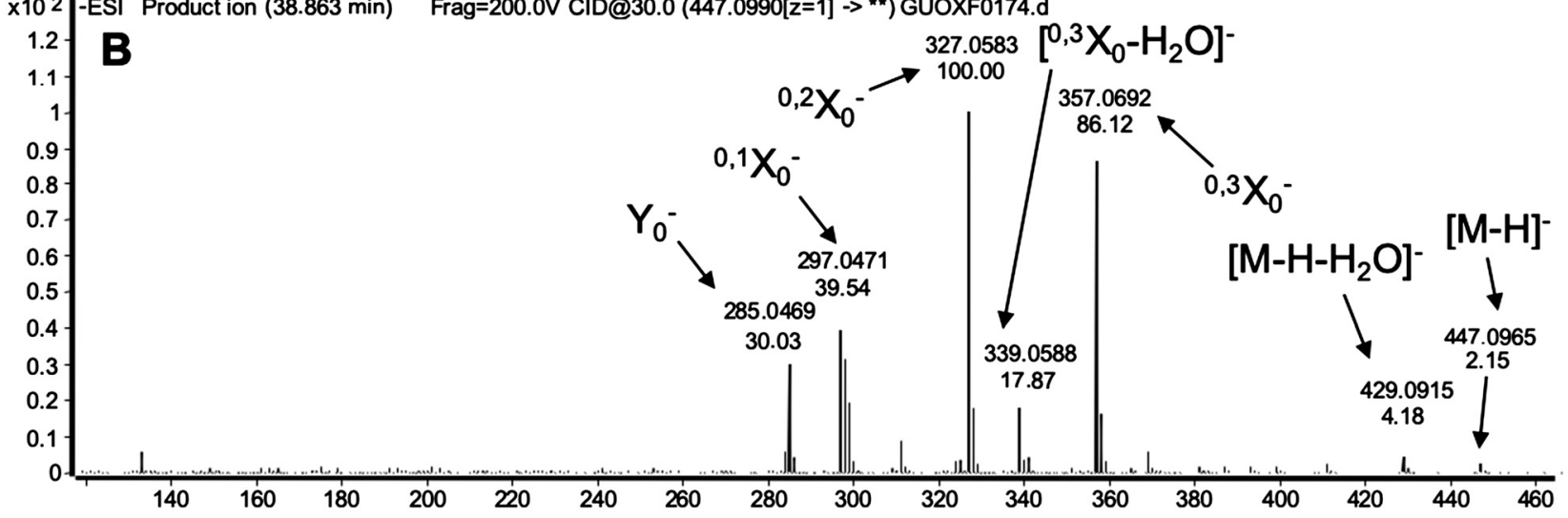

x10 2 -ESI Product ion (45.891 min) Frag=200.0V CID@30.0 (431.1041[z=1] -> **) GUOXF0174.d

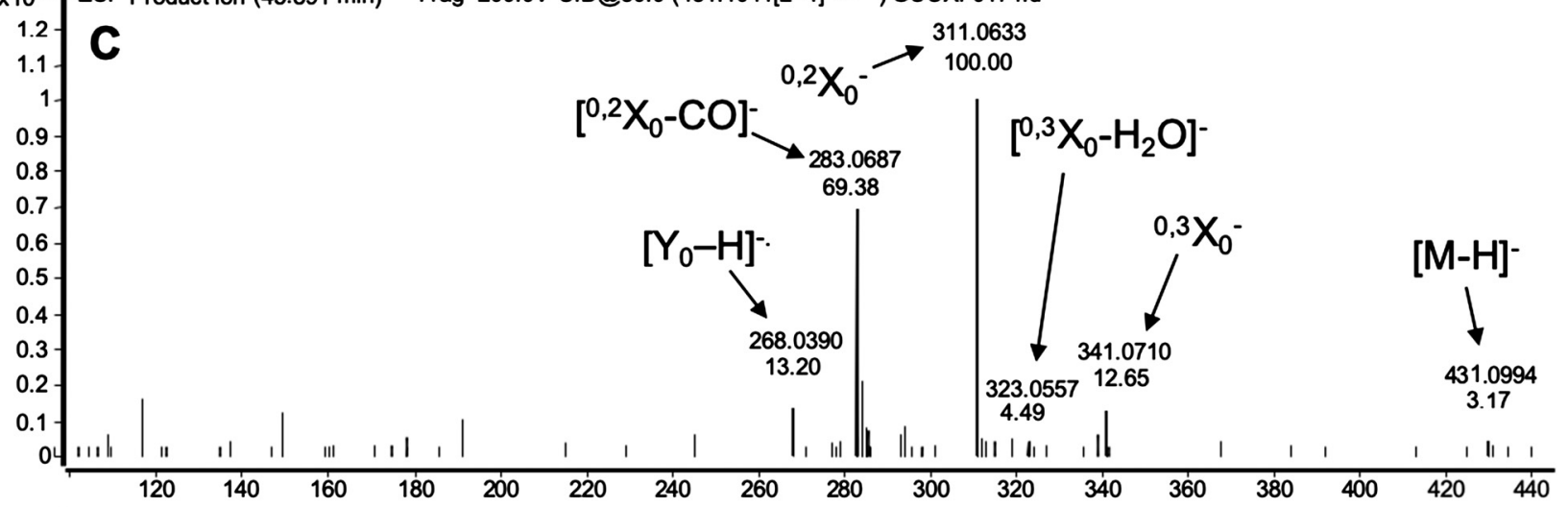

$\times 10^{2}$-ESI Product ion (65.760 min) Frag=200.0V CID@30.0 (431.1041[z=1] $\left.\rightarrow{ }^{\star \star}\right)$ GUOXF0174.d

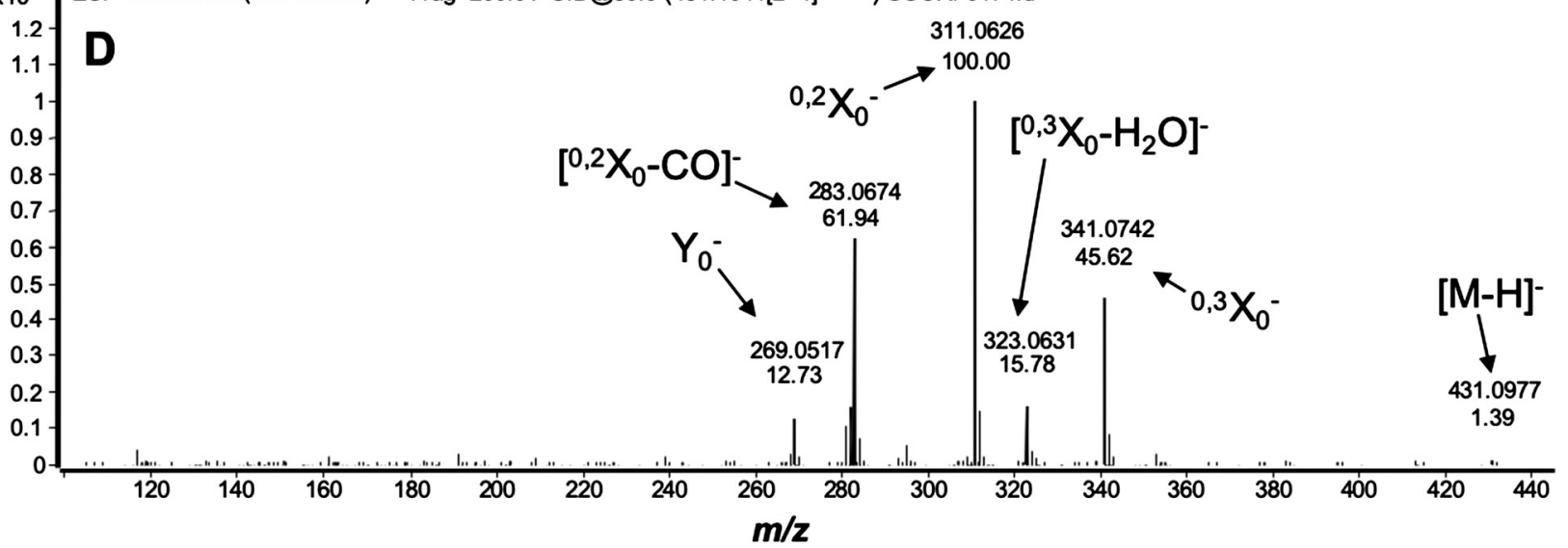

Figure 2. Product ion spectra of the deprotonated ion $[\mathrm{M}-\mathrm{H}]^{-}$of compounds 2,3 , 6, and 7 in the negative ion mode: (A) compound 2, (B) compound 3 , (C) compound 6, and (D) compound 7

abundance of the intraglycoside unit. The differences were observed in the ${ }^{0,3} \mathrm{X}_{0}^{-}$and $\left[{ }^{0,3} \mathrm{X}_{0}-\mathrm{H}_{2} \mathrm{O}\right]^{-}$ions, which displayed lower intensities in vitexin than in isovitexin.
The reference compounds, flavone $C$-glycosides (orientin, isoorientin, vitexin, and isovitexin), were analyzed to determine the characteristic ions for flavone $6-C$ - and $8-C$ - 
glycosides, which have the same skeletal structure; their distinguishing features are the different substituents at the $C-6$ and $C-8$ positions, as well as the different flavone cores with variations around the $6-C$ and $8-C$ positions. The similarities in the fragmentation pathways are due to their similar structures. The fragmentation patterns of flavone $C$-glycosides mainly involve the elimination of sugar groups at $C-6$ and $C-8$ and the cross-ring cleavage of the carbohydrate moiety. The relative intensities of the product ions, ${ }^{0,3} \mathrm{X}_{0}^{-}$and $\left[{ }^{0,3} \mathrm{X}_{0}-\mathrm{H}_{2} \mathrm{O}\right]^{-}$of the two isomers are different, and the product ions of the flavone 6-C-glycoside isomers are significantly more intense than those of the flavonoid 8-C-glycoside isomers because flavone 6-C-glycosides can lose $\mathrm{H}_{2} \mathrm{O}$ between the 2 "-hydroxyl group of the sugar and the 5- or 7-hydroxyl groups of the aglycone. Thus, these characteristic ions were used to differentiate 6- $C$ and $8-C$ isomers [34].

3.3. Identification of Flavone $\boldsymbol{C}$-Glycosides. Compound $8(\mathrm{RT}=74.37 \mathrm{~min})$ showed an $[\mathrm{M}-\mathrm{H}]^{-}$ion at $\mathrm{m} / \mathrm{z} 461.1093$ $\left(\mathrm{C}_{22} \mathrm{H}_{22} \mathrm{O}_{11}\right)$, and its deprotonated ion $[\mathrm{M}-\mathrm{H}]^{-}$yielded a series of major fragment ions at $\mathrm{m} / \mathrm{z} 371.0827\left({ }^{0,3} \mathrm{X}_{0}^{-}\right)$and $341.0784\left({ }^{0,2} \mathrm{X}_{0}^{-}\right)[35,36]$. The product ions at $\mathrm{m} / \mathrm{z} 326.0458$ $\left(\left[{ }^{0,2} \mathrm{X}_{0}-\mathrm{CH}_{3}\right]^{-.}\right)$and $313.0748\left(\left[^{0,2} \mathrm{X}_{0}-\mathrm{CO}\right]^{-}\right)$were produced by the loss of the methyl group (15 Da) and CO $(28 \mathrm{Da})$ from the $m / z 341.0784\left({ }^{0,2} \mathrm{X}_{0}^{-}\right)$ion. The elimination of $163 \mathrm{Da}($ glucose $+\cdot \mathrm{H})$ from the $C$ position produced a fragment ion at $m / z 298.0562\left(\left[\mathrm{Y}_{0}-\mathrm{H}\right]^{-*}\right)$, which indicated that compound 8 was a glucoside derivative of luteolin. The fragment ions at $m / z 371.0827\left({ }^{0,3} \mathrm{X}_{0}^{-}\right)$and $341.0784\left({ }^{0,2} \mathrm{X}_{0}^{-}\right)$of compound 8 were similar to those of orientin, indicating that compound 8 is flavone $8-C$-glycoside. Based on the results discussed above, compound 8 was tentatively identified as luteolin-3'-methoxy-8-C-glucoside, which has also been identified in Citri Reticulatae Pericarpium [37] and Baizhu Shaoyao San [30]. To the best of our knowledge, this compound has been found in PES leaves for the first time.

Compound $9(\mathrm{RT}=81.21 \mathrm{~min})$ has an $[\mathrm{M}-\mathrm{H}]^{-}$ion at $\mathrm{m} / \mathrm{z}$ 461.1068 , which suggests a formula of $\mathrm{C}_{22} \mathrm{H}_{22} \mathrm{O}_{11}$. The tandem mass spectrum of compound 9 contained major product ions at $371.0773\left({ }^{0,3} \mathrm{X}_{0}^{-}\right)$and $341.0619\left({ }^{0,2} \mathrm{X}_{0}^{-}\right)$[38]. The product ions at $\mathrm{m} / \mathrm{z} 326.0426\left(\left[^{0,2} \mathrm{X}_{0}-\mathrm{CH}_{3}\right]^{-\bullet}\right)$ and 313.0710 $\left(\left[{ }^{0,2} \mathrm{X}_{0}-\mathrm{CO}\right]^{-}\right)$were produced by the loss of the methyl group (15 Da) and CO (28 Da) from the $m / z 341.0619\left({ }^{0,2} \mathrm{X}_{0}^{-}\right)$ ion. The fragment ion at $m / z 371.0773\left({ }^{0,3} \mathrm{X}_{0}^{-}\right)$of compound 9 was identical to that of isoorientin, which indicated that they are both flavone 6-C-glycosides. The fragmentation pathways of compound 9 are similar to those of compound 8. Thus, compound 9 was tentatively assigned as luteolin-3'-methoxy6 - $C$-glucoside. To the best of our knowledge, this is the first time this compound has been found in PES leaves.

The retention time of compound 11 was $98.07 \mathrm{~min}$, and it gave a deprotonated ion $[\mathrm{M}-\mathrm{H}]^{-}$at $\mathrm{m} / \mathrm{z}$ 417.0799. The product ion at $m / z 399.0666\left(\left[\mathrm{M}-\mathrm{H}-\mathrm{H}_{2} \mathrm{O}\right]^{-}\right)$arose from the elimination of $\mathrm{H}_{2} \mathrm{O}(18 \mathrm{Da})$. The fragment ions at $\mathrm{m} / \mathrm{z}$ $357.0608\left({ }^{0,3} \mathrm{X}_{0}^{-}\right), 327.0503\left({ }^{0,2} \mathrm{X}_{0}^{-}\right)$, and $297.0472\left({ }^{0,1} \mathrm{X}_{0}^{-}\right)$correspond to the losses of $\mathrm{C}_{2} \mathrm{H}_{4} \mathrm{O}_{2}(60 \mathrm{Da}), \mathrm{C}_{3} \mathrm{H}_{6} \mathrm{O}_{3}(90 \mathrm{Da})$, and $\mathrm{C}_{4} \mathrm{H}_{8} \mathrm{O}_{4}(120 \mathrm{Da})$ from the deprotonated ion at $\mathrm{m} / \mathrm{z}$ $417.0789\left([\mathrm{M}-\mathrm{H}]^{-}\right)$, which are due to the cross-ring cleavage of the glucose moiety. The minor fragment ion at $\mathrm{m} / \mathrm{z}$ $339.0503\left(\left[{ }^{0,3} \mathrm{X}_{0}-\mathrm{H}_{2} \mathrm{O}\right]^{-}\right)$was due to the loss of $\mathrm{H}_{2} \mathrm{O}$ $(18 \mathrm{Da})$ from the fragment ion at $m / z 357.0608\left({ }^{0,3} \mathrm{X}_{0}^{-}\right)$. In addition, the product ion at $\mathrm{m} / \mathrm{z} 285.0415\left(\mathrm{Y}_{0}^{-}\right)$was formed from the loss of an arabinose molecule (132 Da), which indicated that compound 11 was an arabinoside derivative of luteolin. The fragment ions ${ }^{0,3} \mathrm{X}_{0}^{-}$and $\left[{ }^{0,3} \mathrm{X}_{0}-\mathrm{H}_{2} \mathrm{O}\right]^{-}$are similar to those of isoorientin, which indicates that they are flavone 6-Cglycosides. Thus, compound 11 was tentatively identified as luteolin-6-C-arabinoside. This compound has been reported in
Adhatoda vasica leaves [39]; to the best of our knowledge, this is the first time this compound was found in PES leaves.

In PES leaves, 3 compounds have been tentatively identified as flavone $C$-glycosides for the first time. The relative abundance of the characteristic ion $\left[\mathrm{Y}_{0}-\mathrm{H}\right]^{-}$of flavone $3^{\prime}-$ methoxy- $C$-glycoside is significantly higher than that of flavone $C$-glycoside, possibly because methoxylation can promote the formation of $\left[\mathrm{Y}_{0}-\mathrm{H}\right]^{-\bullet}$. The relative abundances of the characteristic ions ${ }^{0,3} \mathrm{X}_{0}^{-},{ }^{0,2} \mathrm{X}_{0}^{-}$, and ${ }^{0,1} \mathrm{X}_{0}^{-}$of the flavonoid $C$-glycosides with different glycosyl groups on the same aglycone are significantly different. Therefore, these fragment ions can be used to identify compounds of this class with different substituents on the same flavonoid aglycone skeletons. Product ion spectra and the main fragmentation pathways of deprotonated ion $[\mathrm{M}-\mathrm{H}]^{-}$of compounds 8,9 , and 11 in (-)ESIMS/MS are shown in Figure 3.

3.4. Identification of Flavone $\boldsymbol{O}$-Glycosides. Compound $12(\mathrm{RT}=107.28 \mathrm{~min})$ displayed an $[\mathrm{M}-\mathrm{H}]^{-}$ion at $\mathrm{m} / \mathrm{z}$ 491.1233 and abundant $\mathrm{Y}_{0}^{-}$ion at $\mathrm{m} / \mathrm{z} 329.0679$, indicating the presence of a glucose group $(162 \mathrm{Da})$. The tandem mass spectrum showed fragment ions at $m / z 314.0425\left(\left[\mathrm{Y}_{0}-\mathrm{CH}_{3}\right]^{-\bullet}\right)$ and $299.0204\left(\left[\mathrm{Y}_{0}-2 \mathrm{CH}_{3}\right]^{-}\right)$, which indicated the presence of a tricin-derived skeleton. Furthermore, compound 12 yielded low intensity fragment ions at $m / z 476.0862\left(\left[\mathrm{M}-\mathrm{H}-\mathrm{CH}_{3}\right]^{-\bullet}\right)$ and $461.0649\left(\left[\mathrm{M}-\mathrm{H}-2 \mathrm{CH}_{3}\right]^{-}\right)$because the glucose at the 4 ' position sterically prevents the loss of the methyl group, which indicated that compound 12 is a flavone 4'-Oglycoside. Thus, compound 12 was tentatively assigned as tricin-4'-O-glucoside. Although compound 12 has previously been reported in the leaves of Sasa kurilensis var. Gigantea [40], to the best of our knowledge, this is the first time it has been found in PES leaves.

Compound $13(\mathrm{RT}=115.05 \mathrm{~min})$ showed an $[\mathrm{M}-\mathrm{H}]^{-}$ion at $m / z$ 491.1192. The two abundant fragment ions were found in its tandem mass spectrum at $m / z 476.0946\left(\left[\mathrm{M}-\mathrm{H}-\mathrm{CH}_{3}\right]^{-\bullet}\right)$ and $461.0714\left(\left[\mathrm{M}-\mathrm{H}-2 \mathrm{CH}_{3}\right]^{\top}\right)$. Compared with compound 12, two characteristic ions $\left(\left[\mathrm{M}-\mathrm{H}-\mathrm{CH}_{3}\right]^{\bullet}\right.$ and $\left.\left[\mathrm{M}-\mathrm{H}-2 \mathrm{CH}_{3}\right]^{-}\right)$ presented high intensities, and deprotonated ion produced the most prominent ions at $\mathrm{m} / z 313.0355\left(\mathrm{Z}_{0}^{-}\right)$[41], which indicated that compound 13 is the 7-O-glucoside derivative of tricin. The product ion $\left[\mathrm{Y}_{0}-\mathrm{H}\right]^{-\bullet}$ at $\mathrm{m} / z 328.0593$ indicated the presence of a glucose group. The minor ions at $\mathrm{m} / \mathrm{z} 299.0204$ $\left(\left[\mathrm{Z}_{0}-\mathrm{CH}_{2}\right]^{-}\right)$and $285.0419\left(\left[\mathrm{Z}_{0}-2 \mathrm{CH}_{2}\right]^{-}\right)$were formed from the successive eliminations of $14 \mathrm{Da}($ methyl $-\bullet \mathrm{H})$ from the $\mathrm{m} / \mathrm{z} 313.0355$ ion $\left(\mathrm{Z}_{0}^{-}\right)$. According to the above-deduced fragmentation patterns of compound 13, it was tentatively identified as tricin-7-O-glucoside, which has been reported to be present in Meconopsis horridula [42] and Citrus reticulata Blanco [31].

Two compounds were tentatively characterized as flavonoid $O$-glycosides. The flavonoid $O$-glycoside isomers have distinct differences in the relative abundances of the $\mathrm{Y}_{0}^{-}$and $\left[\mathrm{Y}_{0}-\mathrm{H}\right]^{-\bullet}$ ions and in the formation of diagnostic ions, such as $\mathrm{Z}_{0}^{-},\left[\mathrm{M}-\mathrm{H}-\mathrm{CH}_{3}\right]^{-\bullet}$ and $\left[\mathrm{M}-\mathrm{H}-2 \mathrm{CH}_{3}\right]^{-}$. Compound 12 yielded low intensity fragment ions at $\mathrm{m} / \mathrm{z} 476.0862$ $\left(\left[\mathrm{M}-\mathrm{H}-\mathrm{CH}_{3}\right]^{-\bullet}\right)$ and $461.0649\left(\left[\mathrm{M}-\mathrm{H}-2 \mathrm{CH}_{3}\right]^{-}\right)$because the glucose at the $4^{\prime}$ position sterically prevents the loss of the methyl group, which indicated that compound 12 is a flavone 4'-O-glycoside. Compared with compound 12 , compound 13 yielded two characteristic ions $\left(\left[\mathrm{M}-\mathrm{H}-\mathrm{CH}_{3}\right]^{-\bullet}\right.$ and $\left[\mathrm{M}-\mathrm{H}-2 \mathrm{CH}_{3}\right]^{-}$) presented with high intensities. Product ion spectra and the main fragmentation pathways of deprotonated ion $[\mathrm{M}-\mathrm{H}]^{-}$of compounds 12 and 13 in (-)ESI-MS/ MS are shown in Figure 4.

3.5. Identification of Flavone $\boldsymbol{C}$-Diglycosides. Compound $4(\mathrm{RT}=33.71 \mathrm{~min})$ gave an $[\mathrm{M}-\mathrm{H}]^{-}$ion at $\mathrm{m} / \mathrm{z} 609.1502$. The tandem mass spectrum of this compound showed a 


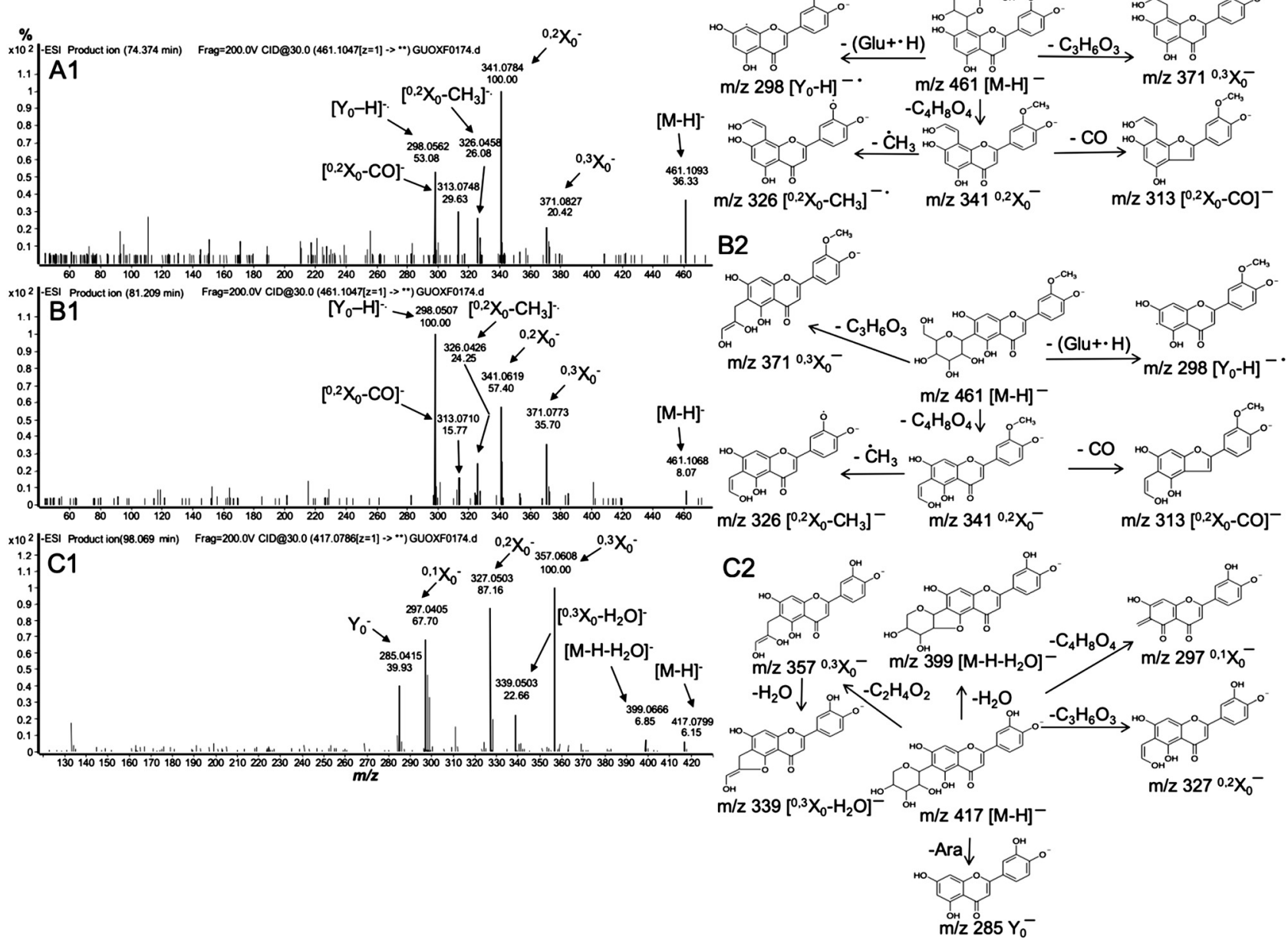

Figure 3. Product ion spectra and the main fragmentation pathways of the deprotonated ion $[\mathrm{M}-\mathrm{H}]^{-}$of compound 8 , 9 , and 11 in (-)ESI-MS/ MS: (A) compound 8, (B) compound 9, and (C) compound 11

fragment ion at $m / z 447.0990\left(\mathrm{Y}_{1}^{-}\right)$, which corresponded to the loss of a glucose moiety $(162 \mathrm{Da})$ from the $[\mathrm{M}-\mathrm{H}]^{-}$, suggesting the presence of a glucose group. The fragmentation pathways of the product ions at $m / z 489.1123 \quad\left({ }^{0,2} \mathrm{X}_{0}^{-}\right)$, $357.0652\left(\left[\mathrm{Y}_{1}{ }^{-}{ }^{0,3} \mathrm{~A}_{2}\right]\right), 339.0669\left(\left[\mathrm{Y}_{1}{ }^{-}{ }^{0,3} \mathrm{~A}_{2}-\mathrm{H}_{2} \mathrm{O}\right]^{-}\right)$, and $327.0580\left(\left[\mathrm{Y}_{1}-^{0,2} \mathrm{~A}_{2}\right]^{-}\right)$were identical to those of isoorientin,
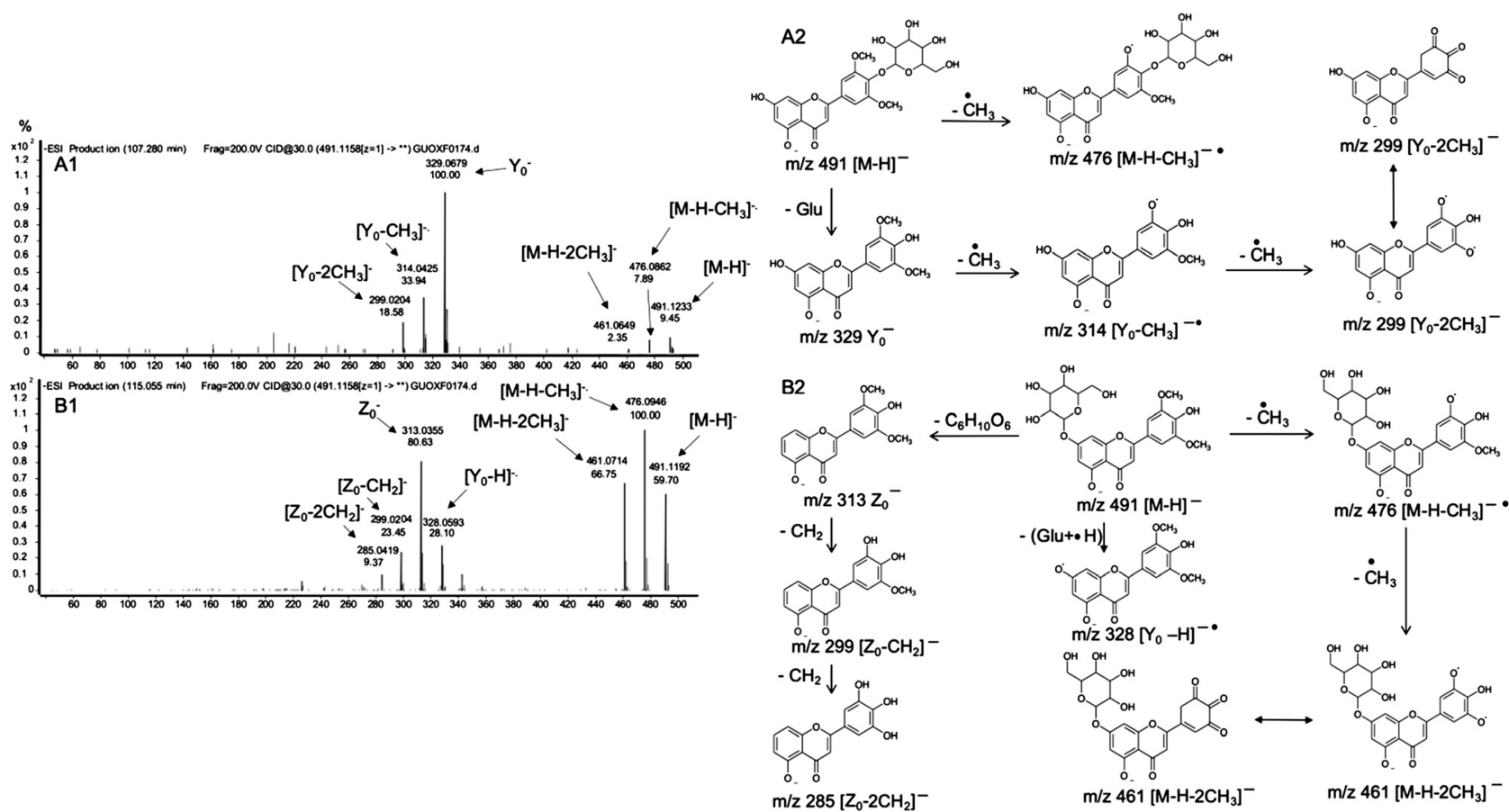

$\mathrm{m} / \mathrm{z} 461\left[\mathrm{M}-\mathrm{H}-2 \mathrm{CH}_{3}\right]^{-}$

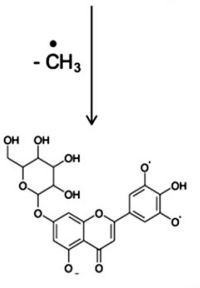

Figure 4. Product ion spectra and the main fragmentation pathways of the deprotonated ion $[\mathrm{M}-\mathrm{H}]^{-}$of compounds 12 and 13 in (-)ESI-MS/ MS: (A) compound 12 and (B) compound 13 
which indicated that compound 4 was a flavone 6- $C$-glycoside. The product ions at $\mathrm{m} / \mathrm{z} 429.0924\left(\left[\mathrm{Y}_{1}-\mathrm{H}_{2} \mathrm{O}\right]^{-}\right), 339.0669$ $\left(\left[\mathrm{Y}_{1}{ }^{-}{ }^{0,3} \mathrm{~A}_{2}-\mathrm{H}_{2} \mathrm{O}\right]^{-}\right)$, and $309.0453\left(\left[\mathrm{Y}_{1}-^{0,2} \mathrm{~A}_{2}-\mathrm{H}_{2} \mathrm{O}\right]^{-}\right)$were formed after elimination of $\mathrm{H}_{2} \mathrm{O}(18 \mathrm{Da})$ from the $\mathrm{Y}_{1}^{-}$, $\left[\mathrm{Y}_{1}-{ }^{0,3} \mathrm{~A}_{2}\right]^{-}$, and $\left[\mathrm{Y}_{1}-{ }^{0,2} \mathrm{~A}_{2}\right]^{-}$ions, respectively. The prominent ion at $\mathrm{m} / \mathrm{z} 285.0442\left(\mathrm{Y}_{0}^{-}\right)$indicated that compound 4 was a diglycoside derivative of luteolin. Therefore, compound 4 was tentatively identified as isoorientin-2"-O-glucoside. This compound has been previously reported in the literature [43], but to the best of our knowledge, this is the first time it has been found in PES leaves.

The retention time of compound 5 was $34.97 \mathrm{~min}$. ESIQTOF/MS gave deprotonated ion $[\mathrm{M}-\mathrm{H}]^{-}$at $\mathrm{m} / \mathrm{z} 579.1318$. The observation of the characteristic fragment ion at $\mathrm{m} / \mathrm{z}$ $447.1043\left(\mathrm{Y}_{1}^{-}\right)$corresponded to the loss of an arabinose moiety (132 Da). Compound 5 yielded moderately abundant characteristic fragment ions at $m / z \quad 357.0701\left(\left[\mathrm{Y}_{1}-^{0,3} \mathrm{~A}_{2}\right]^{-}\right)$, $327.0588\left(\left[\mathrm{Y}_{1}-{ }^{0,2} \mathrm{~A}_{2}\right]^{-}\right)$, and $339.0577\left(\left[\mathrm{Y}_{1}{ }^{0,3} \mathrm{~A}_{2}-\mathrm{H}_{2} \mathrm{O}\right]^{-}\right)$, indicating the presence of a 6-C-glycosyl unit. At $\mathrm{m} / \mathrm{z}$ $459.1029\left({ }^{0,2} \mathrm{X}_{0}^{-}\right)$, compound 5 produced a predominant ion, which was formed from the loss of $\mathrm{C}_{4} \mathrm{H}_{8} \mathrm{O}_{4}(120 \mathrm{Da})$ from the deprotonated ion. The same fragmentation was also observed for other flavone di-C,O-glycosides due to the presence of a $C$-glycosyl unit. Several minor ions at $\mathrm{m} / \mathrm{z} 429.0925$ ([Y $\left.\left.{ }_{1}-\mathrm{H}_{2} \mathrm{O}\right]^{-}\right), 339.0577\left(\left[\mathrm{Y}_{1}{ }^{-0,3} \mathrm{~A}_{2}-\mathrm{H}_{2} \mathrm{O}\right]^{-}\right)$, and 309.0485 $\left(\left[\mathrm{Y}_{1}{ }^{-}{ }^{0,2} \mathrm{~A}_{2}-\mathrm{H}_{2} \mathrm{O}\right]^{-}\right.$) could be attributed to the losses of $\mathrm{H}_{2} \mathrm{O}$ (18 Da) from $m / z 447.1043\left(\mathrm{Y}_{1}^{-}\right), 357.0701\left(\left[\mathrm{Y}_{1}{ }^{-0,3} \mathrm{~A}_{2}\right]^{-}\right)$, and $327.0588\left(\left[\mathrm{Y}_{1}-^{0,2} \mathrm{~A}_{2}\right]^{-}\right)$, respectively. In addition, the loss of the glucose moiety (162 Da) from the flavonoid aglycone skeleton of $m / z 447.1043\left(\mathrm{Y}_{1}^{-}\right)$led to the formation of the ion at $m / z 285.0471\left(\mathrm{Y}_{0}^{-}\right)$. Based on its MS/MS data and compare with compound 4 , compound 5 was tentatively identified as isoorientin-2"-O-arabinoside, which has been reported to be present in Gypsophila elegans [44]. To the best of our knowledge, this is the first time it has been found in PES leaves.

Compound $10(\mathrm{RT}=76.91 \mathrm{~min})$ gave an $[\mathrm{M}-\mathrm{H}]^{-}$ion at $\mathrm{m} / \mathrm{z}$ 577.1552. In its tandem mass spectrum, the observation of the characteristic fragment ions at $m / z 457.1158\left({ }^{0,2} \mathrm{X}_{0}^{-}\right)$and $431.0808\left(\mathrm{Y}_{1}^{-}\right)$corresponded to the loss of $\mathrm{C}_{4} \mathrm{H}_{8} \mathrm{O}_{4}(120 \mathrm{Da})$ and a rhamnose moiety $(146 \mathrm{Da})$, respectively. The product ion at $m / z 413.0879$ corresponded to $\left[\mathrm{Y}_{1}-\mathrm{H}_{2} \mathrm{O}\right]^{-}$, which was generated due to the loss of $18 \mathrm{Da}\left(\mathrm{H}_{2} \mathrm{O}\right)$ from the $\mathrm{Y}_{1}^{-}$ion. The minor fragment ion at $m / z 353.0675\left(\left[\mathrm{Y}_{1}-\mathrm{H}_{2} \mathrm{O}-{ }^{0,4} \mathrm{~A}_{2}\right]^{-}\right)$ was due to the loss of $\mathrm{C}_{2} \mathrm{H}_{4} \mathrm{O}_{2}(60 \mathrm{Da})$ from the fragment ion

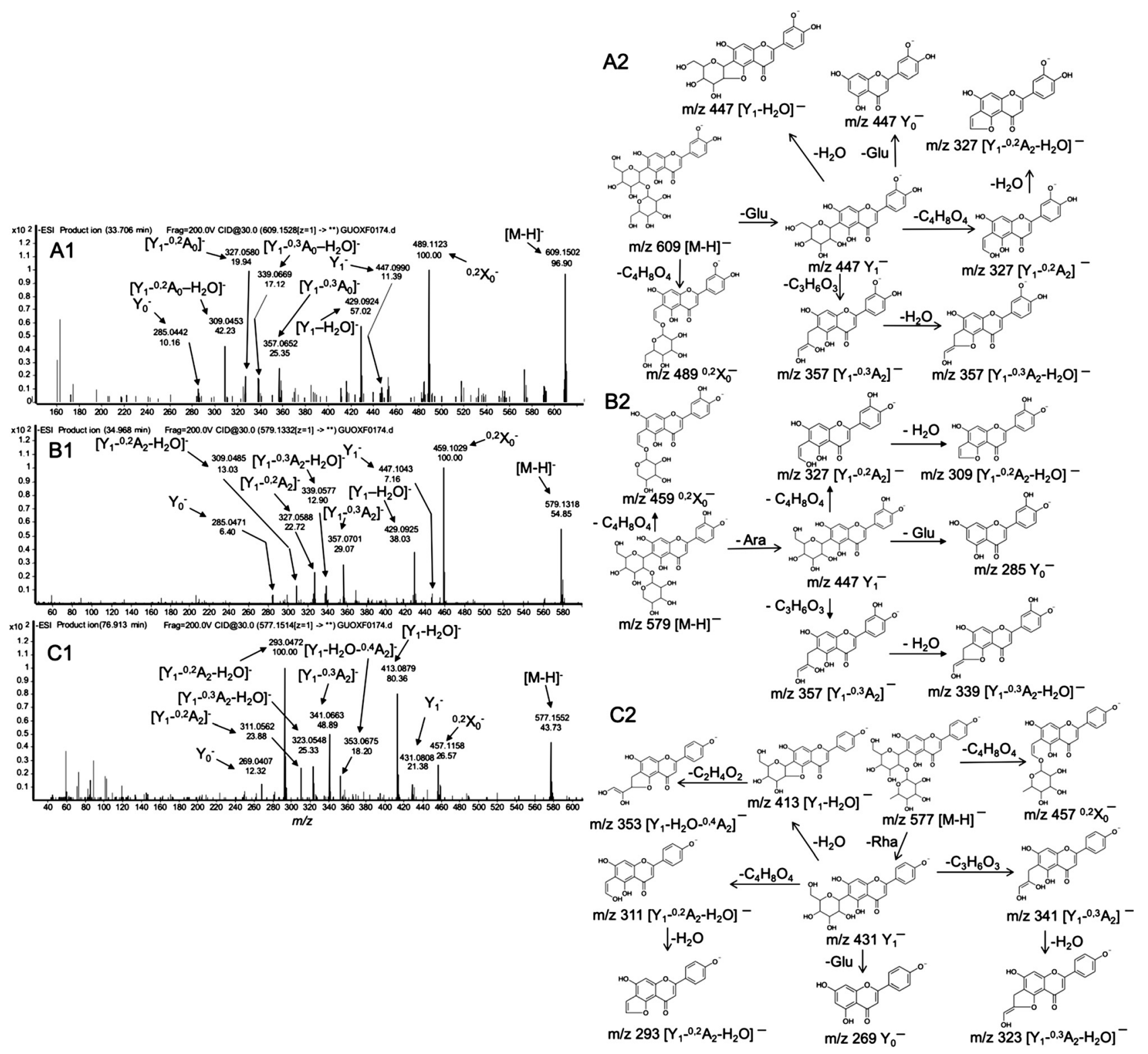

Figure 5. Product ion spectra and the main fragmentation pathways of the deprotonated ion $[\mathrm{M}-\mathrm{H}]^{-}$of compounds 4 , 5, and 10 in (-)ESI-MS/ MS: (A) compound 4, (B) compound 5, and (C) compound 10 
at $\mathrm{m} / z 413.0879\left(\left[\mathrm{Y}_{1}-\mathrm{H}_{2} \mathrm{O}\right]^{-}\right)$. The product ions with $\mathrm{m} / \mathrm{z}$ $341.0663\left(\left[\mathrm{Y}_{1}-^{-{ }^{0,3}} \mathrm{~A}_{2}\right]^{-}\right)$and $311.0562\left(\left[\mathrm{Y}_{1}{ }^{-0,2} \mathrm{~A}_{2}\right]^{-}\right)$were formed due to the losses of $\mathrm{C}_{3} \mathrm{H}_{6} \mathrm{O}_{3}(90 \mathrm{Da})$, and $\mathrm{C}_{4} \mathrm{H}_{8} \mathrm{O}_{4}$ $(120 \mathrm{Da})$ from the abundant ion $\mathrm{Y}_{1}^{-}$, respectively. The fragmentation ions $\left[\mathrm{Y}_{1}-{ }^{0,3} \mathrm{~A}_{2}-\mathrm{H}_{2} \mathrm{O}\right]^{-}$and $\left[\mathrm{Y}_{1}{ }^{-}{ }^{0,2} \mathrm{~A}_{2}-\mathrm{H}_{2} \mathrm{O}\right]^{-}$at $\mathrm{m} / \mathrm{z} 323.0548,293.0472$ with high abundance were identical to that of isovitexin, suggesting the presence of a 6- $C$ substituent. In addition, the elimination of $162 \mathrm{Da}$ (glucose) at the $C-6$ position from $\mathrm{m} / \mathrm{z} 431.0808$ ( $\left.\mathrm{Y}_{1}^{-}\right)$led to the formation of the fragment ion at $m / z 269.0407\left(\mathrm{Y}_{0}^{-}\right)$, indicating that compound 10 is a 6-C-diglycoside derivative of apigenin. Based on the results discussed above, compound 10 was tentatively identified as isovitexin-2"-O-rhamnoside [45]. To the best of our knowledge, this is the first time this compound has been found in PES leaves.

Three compounds were tentatively characterized as flavone $C$-diglycoside. The tandem mass spectrum of compound 4, 5, and 10 showed a fragment ion ${ }^{0,2} \mathrm{X}_{0}^{-}$, which corresponded to the loss of $\mathrm{C}_{4} \mathrm{H}_{8} \mathrm{O}_{4}(120 \mathrm{Da})$ from the $[\mathrm{M}-\mathrm{H}]^{-}$. Then, these
Compounds yielded similar fragment ions $\left[\mathrm{Y}_{1}-\mathrm{H}_{2} \mathrm{O}\right]^{-}$, $\left[\mathrm{Y}_{1}-{ }^{0,3} \mathrm{~A}_{2}\right]^{-},\left[\mathrm{Y}_{1}{ }^{-}{ }^{0,2} \mathrm{~A}_{2}\right]^{-}$, and $\mathrm{Y}_{0}^{-}$due to the losses of $\mathrm{H}_{2} \mathrm{O}$ $(18 \mathrm{Da}), \mathrm{C}_{3} \mathrm{H}_{6} \mathrm{O}_{3}(90 \mathrm{Da})$, and $\mathrm{C}_{4} \mathrm{H}_{8} \mathrm{O}_{4}(120 \mathrm{Da})$ from the abundant ion $\mathrm{Y}_{1}^{-}$. As discussed previously, the major fragments of flavone $C$-diglycosides indicated the cross-ring cleavage of the glycoside moiety. Product ion spectra and the main fragmentation pathways of deprotonated ion $[\mathrm{M}-\mathrm{H}]^{-}$ of compound 4, 5, and 10 in (-)ESI-MS/MS are shown in Figure 5.

3.6. Identification of Flavone di-C,O-Glycosides. Compound 1 ( $\mathrm{RT}=27.43 \mathrm{~min}$ ) was tentatively identified as isovitexin-4'- $O$-glucoside based on the similarity between its MS data and MS/MS fragmentation pattern and the data present in the literature [46]. Compound 1 exhibited a deprotonated ion $[\mathrm{M}-\mathrm{H}]^{-}$at $\mathrm{m} / \mathrm{z} 593.1518$ in its tandem mass spectrum. Product ion spectra of the deprotonated ion $[\mathrm{M}-\mathrm{H}]^{-}$of compounds 1 in $(-)$ ESI-MS/MS are shown in Figure 6 (A1). The MS/MS data showed fragment ions at $\mathrm{m} / \mathrm{z}$ $473.1126\left({ }^{0,2} \mathrm{X}_{1}^{-}\right)$and abundant $\mathrm{Y}_{1}^{-}$ions at $\mathrm{m} / \mathrm{z}$ 431.1056,
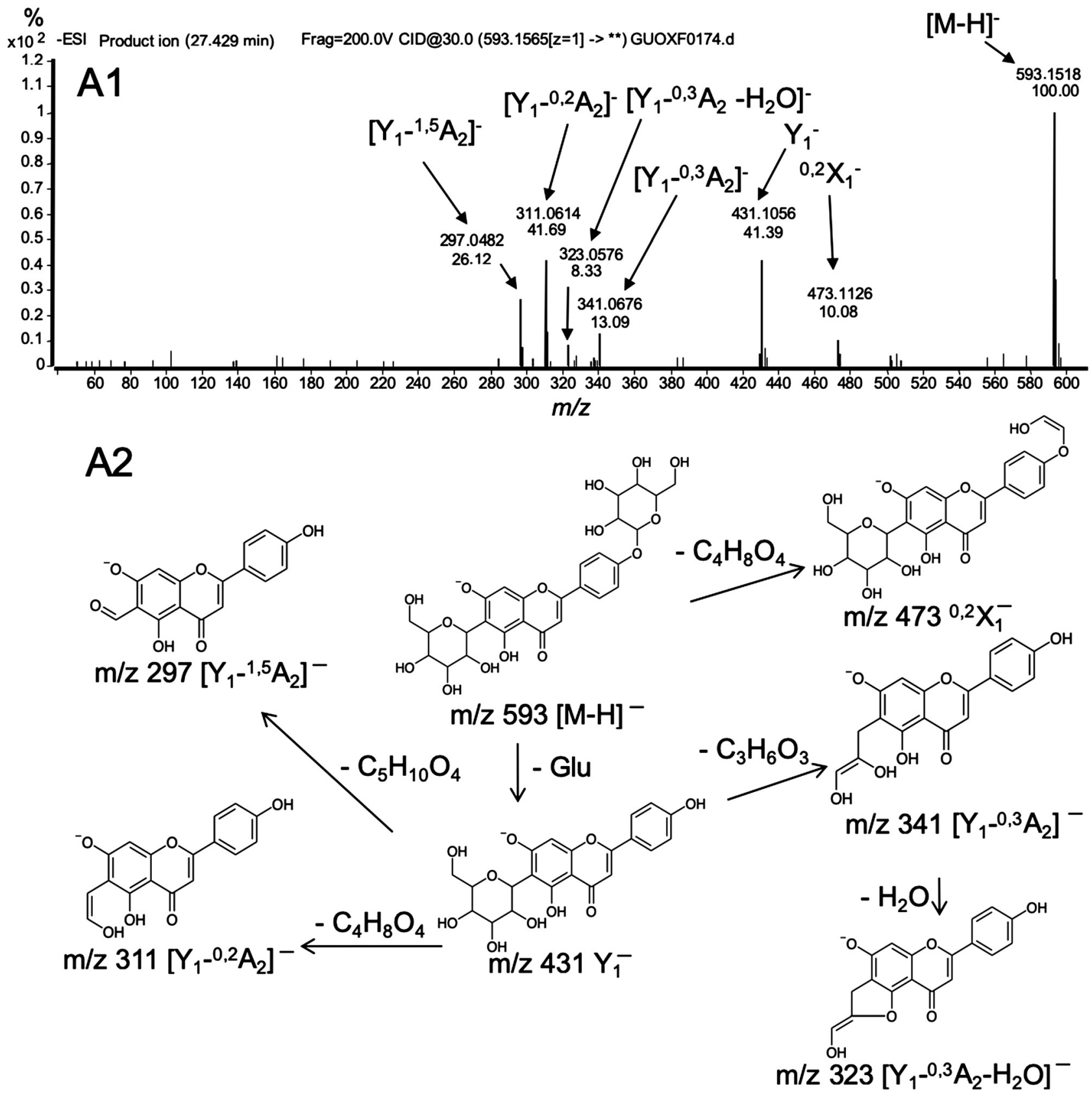

Figure 6. Product ion spectra and the main fragmentation pathways of the deprotonated ion $[\mathrm{M}-\mathrm{H}]^{-}$of compound 1 in $(-)$ ESI-MS/MS 
which indicated the presence of an $O$-glycosyl unit. The fragmentation pathways of the fragment ions at $\mathrm{m} / \mathrm{z} 341.0676$ $\left(\left[\mathrm{Y}_{1}{ }^{-}{ }^{0,3} \mathrm{~A}_{2}\right]^{-}\right), \quad 311.0614 \quad\left(\left[\mathrm{Y}_{1}{ }^{-}{ }^{0,2} \mathrm{~A}_{2}\right]^{-}\right), \quad$ and 297.0482 $\left(\left[\mathrm{Y}_{1}{ }^{1,5} \mathrm{~A}_{2}\right]\right.$ ) indicated the presence of a $C$-hexosyl unit. The products with $m / z 323.0576\left(\left[\mathrm{Y}_{1}{ }^{0,3} \mathrm{~A}_{2}-\mathrm{H}_{2} \mathrm{O}\right]^{-}\right)$were formed by the loss of $\mathrm{H}_{2} \mathrm{O}(18 \mathrm{Da})$ from the minor ion $\left(\left[\mathrm{Y}_{1}-^{0,3} \mathrm{~A}_{2}\right]^{-}\right)$, and the high abundance of the fragment ion at $\mathrm{m} / \mathrm{z} 311.0614$ $\left[\mathrm{Y}_{1}-{ }^{0,2} \mathrm{~A}_{2}\right]^{-}$indicated that the compound is a $6-C$-glucoside derivative of apigenin. To the best of our knowledge, this is the first time this compound has been found in PES leaves.

Compound 1 was tentatively identified as flavone di- $C, O$ glycosides in PES leaves for the first time. In this study, flavone di- $C, O$-glycosides yielded abundant $\mathrm{Y}_{1}^{-}$ions, which indicated the presence of an $O$-glycosyl unit. The flavone di- $C, O$ glycosides preferentially underwent cross-ring cleavage of the sugar attached to the $C$ position. As mentioned above, the proposed main fragmentation pathways of the deprotonated ion $[\mathrm{M}-\mathrm{H}]^{-}$of compound 1 in (-)ESI-MS/MS are displayed in Figure 6(A2).

\section{Conclusions}

In conclusion, an efficient UPLC-QTOF-MS/MS method in the negative ion mode was developed for the structural identification and isomeric differentiation of flavone $C$-glycosides, flavone $O$-glycosides, flavone $C$-diglycosides, and flavone di$C, O$-glycosides in PES leaves. Nine chemical compounds, including 3 flavone $C$-glycosides, 2 flavone $O$-glycosides, 3 flavone $C$-diglycoside, and 1 flavone di- $C, O$-glycosides were tentatively identified, and 4 flavone $C$-glycosides were identified in the PES leaves. This is the first report of these flavonoids (compounds $1,4,5,8,9,10,11$, and 12) in PES leaves. The fragmentation patterns of flavonoids mainly involved in the elimination of glycoside-substituted groups and the cleavage of carbohydrate rings. Fragmentation patterns of flavone $C$-glycosides, flavone $O$-glycosides, flavone $C$-diglycosides, and flavone di- $C, O$-glycosides were investigated. These results have practical applications for the rapid identification and structural characterization of these compounds in crude bioactive extracts or mixtures.

Acknowledgements. This work was supported by the National Natural Science Foundation of China (NSFC) [grant number 31570345].

\section{References}

1. Isagi, Y.; Oda, T.; Fukushima, K.; Lian, C.; Yokogawa, M.; Kaneko, S. J. Plant Res. 2016, 129, 21.

2. Singla, R.; Soni, S.; Patial, V.; Kulurkar, P. M.; Kumari, A.; Mahesh, S.; Padwad, Y. S.; Yadav, S. K. Int. J. Biol. Macromol. 2017, 105, 45.

3. Singla, R.; Soni, S.; Kulurkar, P. M.; Kumari, A.; Mahesh, S.; Patial, V.; Padwad, Y. S.; Yadav, S. K. Carbohydr. Polym. 2017, 155, 152.

4. Wedler, J.; Daubitz, T.; Schlotterbeck, G.; Butterweck, V. Planta. Med. 2014, 80,1678 .

5. Patel, M.; Mehta, P.; Bakshi, S.; Tewari, S. J. Ayurveda Integr. Med. 2016, 7,138

6. Sun, J.; Xun, H.; Yu, J.; Tang, F.; Yue, Y. D.; Guo, X. F. Molecules $\mathbf{2 0 1 5}, 20,15686$.
7. Yang, J. P.; He, H.; Lu, Y. H. J. Agric. Food Chem. 2014, 62, 7760.

8. Gonçalves, S.; Medronho, J.; Moreira, E.; Grosso, C.; Andrade, P. B.; Valentão, P.; Romano, A 3 Biotech. 2018, 8, 88.

9. Pierzynowska, K.; Rzeszótko, A.; Blendowska, A.; Wieczerzak, E.; Rodziewicz-Motowidło, S.; Piotrowska, E.; Wegrzyn, G. Acta. Biochim. Pol. 2018, 65, 325 .

10. Hostetler, G. L.; Ralston, R. A.; Schwartz, S. J. Adv. Nutr. 2017, 8, 423.

11. Guo, X.; Yue, Y.; Tang, F.; Wang, J.; Yao, X. J. Food Biochem. 2013, 37,1745 .

12. Gong, J.; Xia, D.; Huang, J.; Ge, Q.; Mao, J.; Liu, S.; Zhang, Y. J. Med. Food 2015, 18, 453.

13. Sun, Y.; Yang, K.; Cao, Q.; Sun, J.; Xia, Y.; Wang, Y.; Li, W.; Ma, C.; Liu, S. Molecules 2017, 22, 1156.

14. Salar, R. K.; Purewal, S. S.; Sandhu, K. S. 3 Biotech. 2017, 7, 164

15. Grassi, D.; Desideri, G.; Di, G. P.; De, F. M.; Fellini, E.; Cheli, P.; Ferri, L.; Ferri, C. Am. J. Clin. Nutr. 2013, 98, 1660S.

16. Liu, X.; Jia, L.; Gao, Y.; Li, B.; Tu, Y. Acta. Biochim. Biophys. Sin. 2014, 46,920 .

17. Widodo, A.; Widiyanti, P.; Prajogo, B. Afr. J. Infect. Dis. 2018, 12, 36.

18. Yamauchi, K.; Mitsunaga, T.; Afroze, S. H.; Uddin, M. N. Anticancer Res. 2017, 37, 1575 .

19. Feng, J.; Zhang, X. L.; Li, Y. Y.; Cui, Y. Y.; Chen, Y. H. Am. J. Chin. Med. 2016, 44, 1559.

20. Bahrin, L. G.; Hopf, H.; Jones, P. G.; Sarbu, L. G.; Babii, C.; Mihai,

A. C.; Stefan, M.; Birsa, L. M. Beilstein J. Org. Chem. 2016, 12, 1065.

21. Prasain, J. K.; Patel, R.; Kirk, M.; Wilson, L.; Botting, N.; Darley-

Usmar, V. M. Barnes, S. J. Mass Spectrom. 2003, 38, 764.

22. Richard, J. H.; Timothy, R. C.; Chris, D. M.; Mei, W.; Ding, L.; Zhou, Y. Int. J. Mass Spectrom. 2001, 210, 371.

23. Ruiz, A.; Mardones, C.; Vergara, C.; von Baer, D.; Gómez-Alonso, S.; Gómez, M. V.; Hermosín-Gutiérrez, I. J. Agric. Food Chem. 2014, 62, 6918.

24. de Souza, L. M.; Dartora, N.; Scoparo, C. T.; Gorin, P. A.; Iacomini, M.; Sassaki, G. L. J. Chromatogr. A 2016, 1447, 64.

25. Peter, S. R.; Peru, K. M.; Fahlman, B.; McMartin, D. W.; Headley, J. V. J. Environ. Sci. Health B 2015, 50, 819 .

26. Russo, M.; Fanali, C.; Tripodo, G.; Dugo, P.; Muleo, R.; Dugo, L.; De Gara, L.; Mondello, L. Anal. Bioanal. Chem. 2018, 410, 3507.

27. Stobiecki, M Phytochemistry 2000, 54, 237.

28. Cuyckens, F.; Claeys, M. J. Mass Spectrom. 2004, 39, 1.

29. Vukics, V.; Guttman, A. Mass Spectrom Rev. 2010, 29,1

30. Xu, Y.; Cai, H.; Cao, G.; Duan, Y.; Pei, K.; Tu, S.; Zhou, J.; Xie, L.; Sun, D.; Zhao, J.; Liu, J.; Wang, X.; Shen, L. J. Chromatogr. B 2018, 1083 , 110 .

31. Zhao, X. J.; Xing, T. T.; Li, Y. F.; Jiao, B. N.; Jiang, D. J. Sep. Sci. 2018, 41,1947

32. Domon, B.; Costello, C. E. Glycoconjugate J. 1988, 5, 397

33. Ma, Y. L.; Li, Q. M.; van den Heuvel, H.; Claeys, M. Rapid Commun Mass Spectrom. 1997, 11, 1357.

34. Guo, X.; Yue, Y.; Tang, F.; Wang, J.; Yao, Y.; Sun, J. J. Inter. J. Mass Spectrom. 2013, 333, 59

35. da Silva Mathias, M.; Rodrigues de Oliveira, R. Phytochem. Anal. 2019, 30, 73 .

36. Iswaldi, I.; Arráez-Román, D.; Rodríguez-Medina, I.; Beltrán-Debón, R.; Joven, J.; Segura-Carretero, A.; Fernández-Gutiérrez, A. Anal. Bioanal. Chem. 2011, 400, 3643.

37. Zheng, G. D.; Zhou, P.; Yang, H.; Li, Y. S.; Li, P.; Liu, E. H. Food Chem. 2013, 136, 604

38. Abu-Reidah, I. M.; Arráez-Román, D.; Quirantes-Piné, R.; FernándezArroyo, S.; Segura-Carretero, A.; Fernández-Gutiérrez, A. Food Res. Inter. 2012, 46, 108

39. Singh, A.; Kumar, S.; Bajpai, V.; Reddy, T. J.; Rameshkumar, K. B.; Kumar, B. Rapid Commun. Mass Spectrom. 2015, 29, 1095.

40. Hasegawa, T.; Tanaka, A.; Hosoda, A.; Takano, F.; Ohta, T. Phytochemistry 2008, 69, 1419.

41. Dai, B.; Hu, Z.; Li, H.; Yan, C.; Zhang, L. J. Chromatogr. B: Anal. Technol. Biomed. Life Sci. 2015, 978, 54.

42. Liu, J.; Wu, H.; Zheng, F.; Liu, W.; Feng, F.; Xie, N. J. Sep. Sci. 2014, $37,2513$.

43. Kim, B.; Woo, S.; Kim, M. J.; Kwon, S. W.; Lee, J.; Sung, S. H.; Koh, H. J. Food Chem. 2018, 241, 154.

44. Qi, P.; Li, Z.; Chen, M.; Sun, Z.; Huang, C. J. Pharm. Biomed. Anal. 2013, 85,218

45. Sun, Y.; Li, H.; Hu, J.; Li, J.; Fan, Y. W.; Liu, X. R.; Deng, Z. Y. J.

Agric. Food Chem. 2013, 61, 10507.

46. Zhang, H. J. Adav Mater. Res. 2011, 396, 96. 